\title{
EXPERIMENT ON UAV PHOTOGRAMMETRY AND TERRESTRIAL LASER SCANNING FOR ICT-INTEGRATED CONSTRUCTION
}

\author{
N. Takahashi ${ }^{\text {a, }}$, R. Wakutsu ${ }^{\text {a }}$, T. Kato ${ }^{\text {a }}$, T. Wakaizumi ${ }^{\text {a }}$, T. Ooishi ${ }^{\text {a }}$, R. Matsuoka ${ }^{\text {a }}$ \\ ${ }^{a}$ Geospatial Technology Department, Kokusai Kogyo Co., Ltd., Tokyo, Japan - \\ (nae_takahashi, ryuta_wakutsu, takayuki_kato, takuma_wakaizumi, tetsu_ooishi, ryuji_matsuoka)@kk-grp.jp
}

Commission I, ICWG I/II

KEY WORDS: UAV, photogrammetry, terrestrial laser scanning, experiment, accuracy, construction

\begin{abstract}
:
In the 2016 fiscal year the Ministry of Land, Infrastructure, Transport and Tourism of Japan started a program integrating construction and ICT in earthwork and concrete placing. The new program named "i-Construction" focusing on productivity improvement adopts such new technologies as UAV photogrammetry and TLS. We report a field experiment to investigate whether the procedures of UAV photogrammetry and TLS following the standards for "i-Construction" are feasible or not. In the experiment we measured an embankment of about 80 metres by 160 metres immediately after earthwork was done on the embankment. We used two sets of UAV and camera in the experiment. One is a larger UAV enRoute Zion QC730 and its onboard camera Sony $\alpha 6000$. The other is a smaller UAV DJI Phantom 4 and its dedicated onboard camera. Moreover, we used a terrestrial laser scanner FARO Focus3D X330 based on the phase shift principle. The experiment results indicate that the procedures of UAV photogrammetry using a QC730 with an $\alpha 6000$ and TLS using a Focus3D X330 following the standards for "i-Construction" would be feasible. Furthermore, the experiment results show that UAV photogrammetry using a lower price UAV Phantom 4 was unable to satisfy the accuracy requirement for "i-Construction." The cause of the low accuracy by Phantom 4 is under investigation. We also found that the difference of image resolution on the ground would not have a great influence on the measurement accuracy in UAV photogrammetry.
\end{abstract}

\section{INTRODUCTION}

Various unmanned aerial vehicles (UAVs) have been utilized for photogrammetry in the last decade (Eisenbeiss, 2011). Several papers (Gülch, 2011, Haala, et al., 2011, Küng, et al., 2011, Vallet, et al., 2011) to evaluate the potential of UAV photogrammetry were presented at the first UAV-g conference held in Zurich, Switzerland in September 2011. These papers reported that UAV photogrammetry following the procedure of conventional photogrammetry is a promising means for $3 \mathrm{D}$ measurement with sufficient accuracy.

We also conducted an experiment to investigate the feasibility of the deformation measurement of solar panels on reclaimed land by UAV photogrammetry. The experiment result that the RMSE of 220 check points in height measurement was 8.7 millimetres indicated that it would be possible to measure deformation of solar panels with sufficient accuracy by UAV photogrammetry (Matsuoka, et al., 2012).

In recent years several pieces of "shape from motion" (SfM) software based on computer vision technology have been often utilized in UAV photogrammetry. A few papers (Gini, et al., 2013, Greiwe, et al., 2013) to evaluate the potential of UAV photogrammetry with SfM software were presented at the second UAV-g conference held in Rostock, Germany in September 2013. The papers indicated that SfM software is a powerful tool in UAV photogrammetry. The utilization of SfM software in UAV photogrammetry has prompted amateurs to utilize an UAV for 3D measurement.
The Ministry of Land, Infrastructure, Transport and Tourism of Japan (MLIT) started integration of construction and ICT in the whole process of public works; land survey, engineering, construction and maintenance in the 2016 fiscal year. The new MLIT program focusing on productivity improvement especially in earthwork and concrete placing is named " $\mathrm{i}$ Construction". The program adopts such new technologies as UAV and automated construction equipment. Drafts of standards of UAV photogrammetry and terrestrial laser scanning (TLS) for "i-Construction" were issued in March of 2016 (Ministry of Land, Infrastructure, Transport and Tourism of Japan, 2016a).

The standard of UAV photogrammetry by using a piece of SfM software for "i-Construction" includes some requirements in image acquisition planning and measurement accuracy (Ministry of Land, Infrastructure, Transport and Tourism of Japan, 2016b). In image acquisition planning, ground sampling distance (GSD) should be equal to or smaller than ten millimetres. As for an overlapping ratio, that of successive images along a flight strip, which is called OL for short in the paper, should be equal to or greater than $90 \%$, and that of adjacent flight strips, which is called SL for short, should be equal to or greater than $60 \%$. As for measurement accuracy, difference of each coordinate $X, Y$, and $Z$ from the field surveying result at every check point should be equal to or smaller than 50 millimetres.

* Corresponding author 
Given this background, we investigated whether the procedures of UAV photogrammetry and TLS following the standards for "i-Construction" are feasible or not. Moreover we intended to investigate the effect on measurement accuracy in UAV photogrammetry by comparing different kinds of UAV systems, and by comparing different conditions of image acquisition, such as GSD and OL.

\section{OUTLINE OF THE FIELD EXPERIMENT}

We conducted a field experiment to investigate the feasibility of UAV photogrammetry and TLS for "i-Construction" on November 7 and 8, 2016.

\subsection{Test field}

The field experiment was executed at the right bank of the Edo River. The test field lies about 50 kilometres north of the centre of Tokyo is a reinforcement site of the river embankment. In the experiment we measured an embankment of about 80 metres by 160 metres immediately after earthwork was done on the embankment.

Figure 1 shows the test field. This image was acquired by an UAV on October 13, 2016. Figure 2 shows terrestrial images acquired in the field experiment. Figure 3 shows a DSM obtained by TLS in the field experiment. The surface of the experiment field had a smooth slope, and the difference between the highest and the lowest points was approximately 10 meter.

\subsection{Control points and check points}

As for control points and check points the standard of UAV photogrammetry for "i-Construction" requires the followings:

(1) A control point outside the target area should be set up so that the distance between neighbouring outside control points is equal to or smaller than 100 meters.

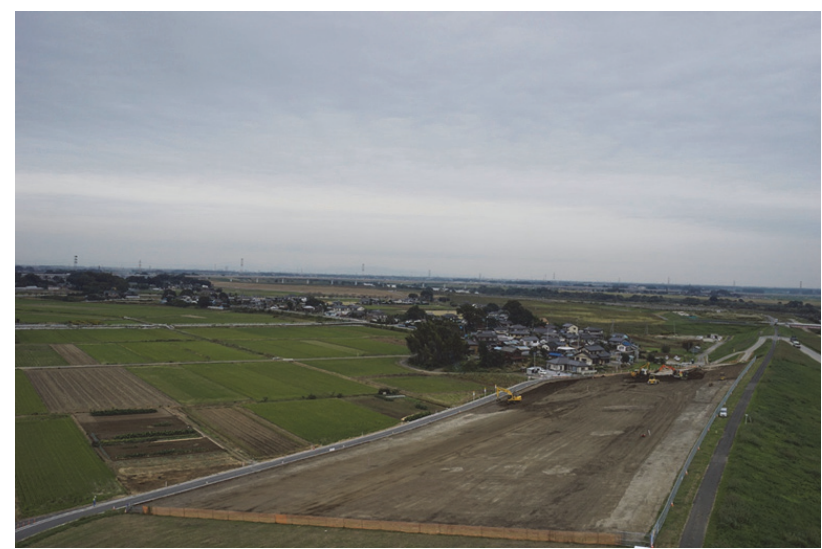

Figure 1. Test field as of October 13, 2016
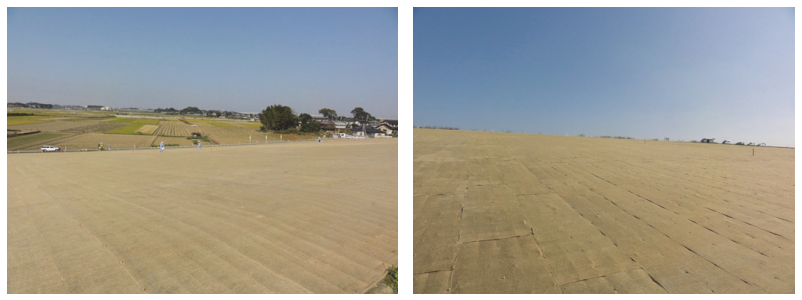

Figure 2. Test field as of November 7, 2016
(2) A control point inside the target area should be set up so that the distance between every neighbouring control points is equal to or smaller than 200 meters.

(3) A check point outside the target area should be set up at every two sides of the polygon composed of control points located outside the target area.

(4) A check point inside the target area should be uniformly distributed every $0.04 \mathrm{~km}^{2}$.

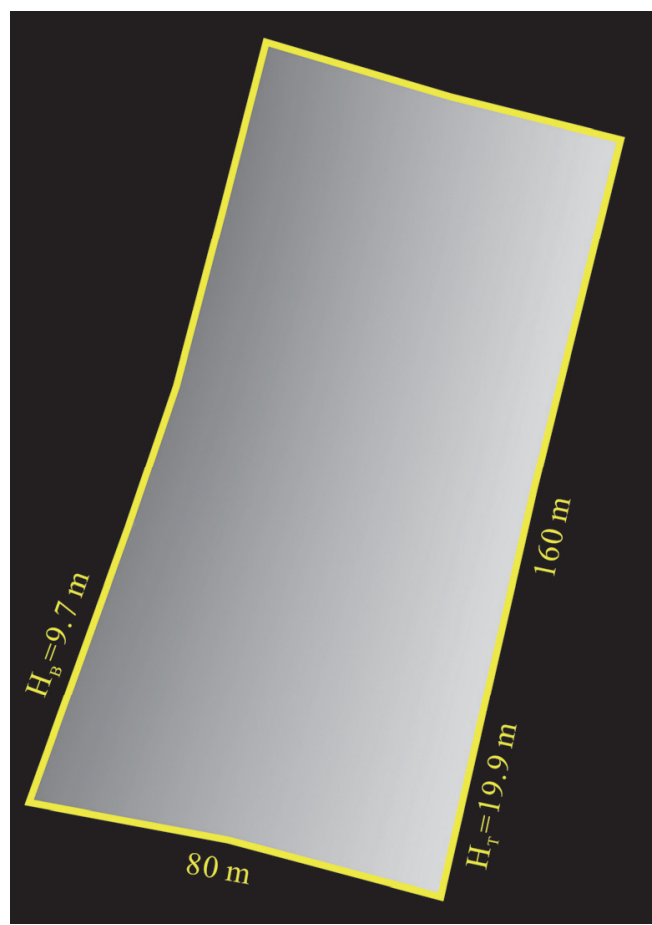

Figure 3. DSM obtained by TLS

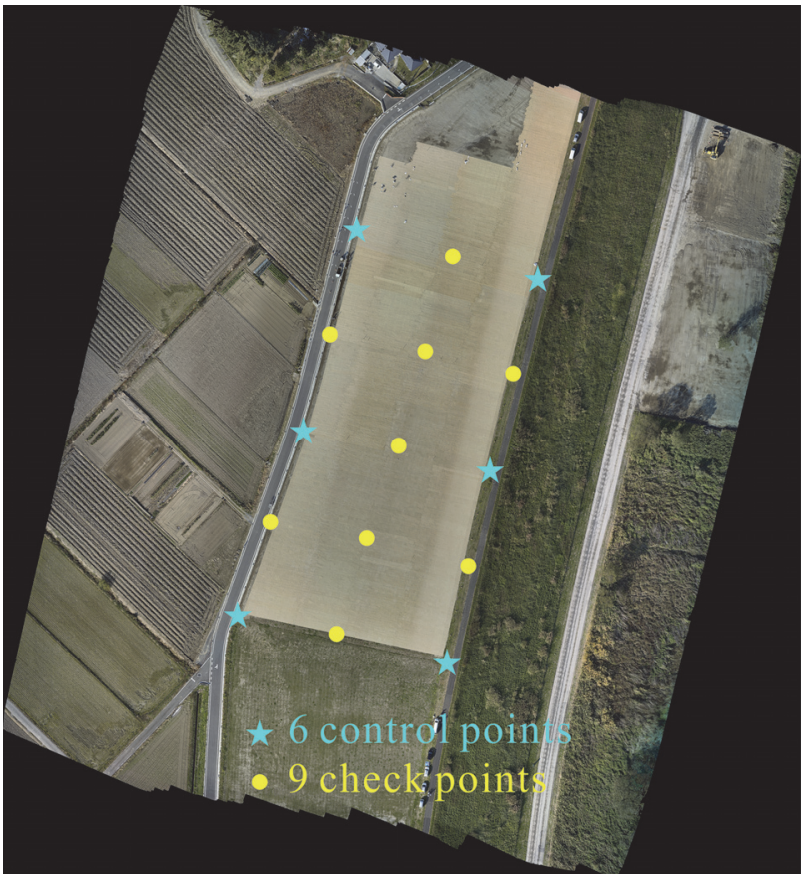

Figure 4. Control points and check points 
Figure 4 shows the distribution of six control points and nine check points we set up in the experiment.

The standard of UAV photogrammetry for "i-Construction" requires six control points outside the target area, and three check points also outside the target area. In the experiment, we established six control points outside the area following the standard of UAV photogrammetry for "i-Construction". On the other hand, we set up nine check points. Six of them were outside the area and the other three were inside.

At each control point and check point, we set up a black and white square target of 300 millimetres by 300 millimetres. Field surveying for ground control was conducted using a total station. The expected positioning accuracy of the ground control was five millimetres.

\subsection{Utilized sets of UAV and camera}

We used two sets of UAV and camera in the experiment. One is a larger UAV enRoute Zion QC730 and its onboard camera Sony $\alpha 6000$. QC730 is one of the drones used especially for surveying in Japan. The diagonal size of QC730 is approximately 730 millimetres, and $\alpha 6000$ has a 24 megapixels sensor. Figure 5 and Figure 6 show QC730 and $\alpha 6000$ respectively.

The other is a smaller UAV DJI Phantom 4 and its dedicated onboard camera. Phantom 4 is known as one of the most popular camera drones in the world. The diagonal size of Phantom 4 is 350 millimetres, which is nearly half of QC730, and its camera has a 12 megapixels sensor. Figure 7 and Figure 8 show Phantom 4 and its dedicated camera respectively.

Table 1 shows the specifications of cameras onboard QC730 and Phantom 4.

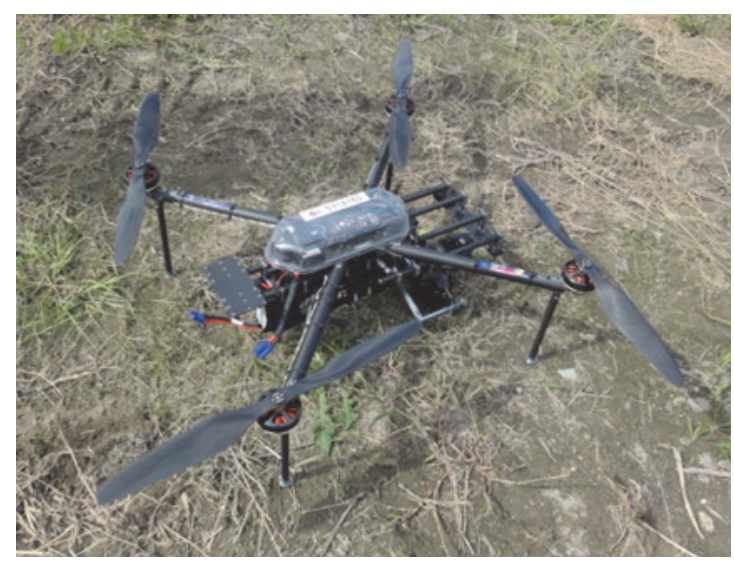

Figure 5. enRoute Zion QC730
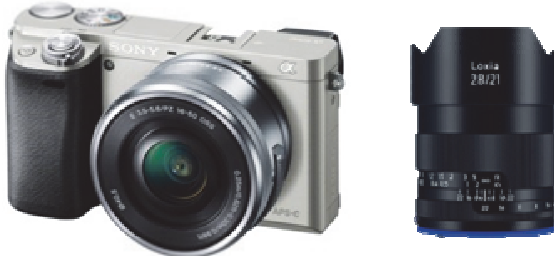

Figure 6 . Sony $\alpha 6000$

\subsection{Image acquisition plans}

In the experiment we made six image acquisition plans as Table 2 shows. Flight numbers 1 to 3 were planned for QC730, and flight numbers 4 to 6 were planned for Phantom 4. As for image overlapping, all of the plans were made so that OL should be $90 \%$ and SL should be $60 \%$. Flight numbers 1 and 4 were planned for 10 millimetres GSD, flight numbers 2 and 5 for 15 millimetres GSD, and flight numbers 3 and 6 for 20 millimetres GSD. Acquired images were planned to be processed by Pix4Dmapper Pro.

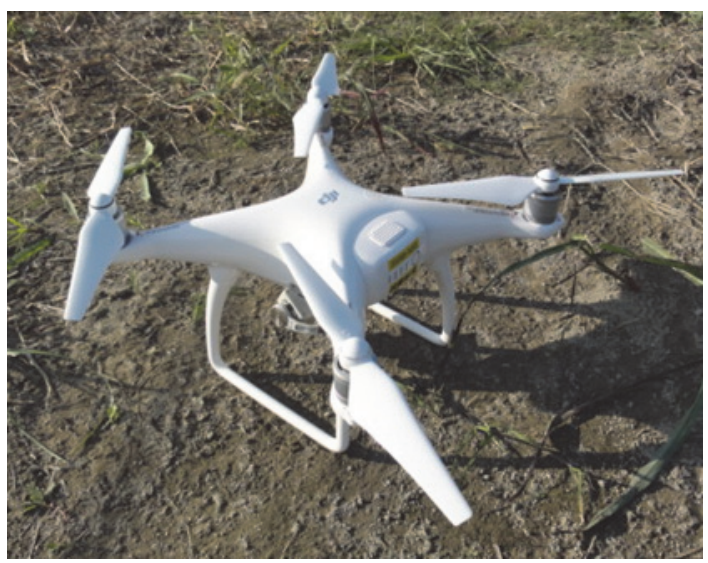

Figure 7. DJI Phantom 4

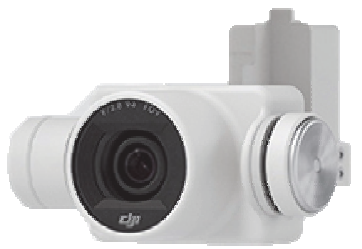

Figure 8. DJI Phantom 4 dedicated onboard camera

\begin{tabular}{|c|c|c|}
\hline & QC730 & Phantom 4 \\
\hline $\begin{array}{c}\text { Sensor size } \\
(\mathrm{mm})\end{array}$ & $\begin{array}{c}\text { APS-C } \\
(23.5 \times 15.6)\end{array}$ & $\begin{array}{c}1 / 2.3 \text { Type } \\
(6.20 \times 4.65)\end{array}$ \\
\hline $\begin{array}{c}\text { Image size } \\
\text { (pixels) }\end{array}$ & $6000 \times 4000$ & $4000 \times 3000$ \\
\hline $\begin{array}{c}\text { Unit cell size } \\
(\mu \mathrm{m})\end{array}$ & $3.9 \times 3.9$ & $1.55 \times 1.55$ \\
\hline $\begin{array}{c}\text { Focal length } \\
(\mathrm{mm})\end{array}$ & 21 & 3.4 \\
\hline $\begin{array}{c}35 \mathrm{~mm} \text { film equivalent } \\
\text { focal length (mm) }\end{array}$ & 32 & 20 \\
\hline
\end{tabular}

Table 1. Specifications of cameras onboard QC730 and Phantom 4 


\subsection{Utilized terrestrial laser scanner}

Figure 9 shows a terrestrial laser scanner FARO Focus3D X330 used in the experiment. Focus3D X330, based on the phase shift principle, is compact and can acquire precise point clouds. It can scan objects up to 330 metres away with the ranging error of 2 millimetres. Table 3. Shows the specification of Focus3D $\mathrm{X} 330$.

\subsection{TLS observation plan}

Figure 10 show the plan for TLS made in the experiment. Since the range of measurement by TLS is restricted to 100 metres in the standard of TLS for "i-Construction" (Ministry of Land,

\begin{tabular}{|c|c|c|c|}
\hline Flight & UAV & Flying height & \multicolumn{1}{|c|}{ GSD } \\
\hline 1 & QC730 & $50 \mathrm{~m}$ & $10 \mathrm{~mm}$ \\
\hline 2 & QC730 & $75 \mathrm{~m}$ & $15 \mathrm{~mm}$ \\
\hline 3 & QC730 & $100 \mathrm{~m}$ & $20 \mathrm{~mm}$ \\
\hline 4 & Phantom 4 & $22 \mathrm{~m}$ & $10 \mathrm{~mm}$ \\
\hline 5 & Phantom 4 & $33 \mathrm{~m}$ & $15 \mathrm{~mm}$ \\
\hline 6 & Phantom 4 & $44 \mathrm{~m}$ & $20 \mathrm{~mm}$ \\
\hline
\end{tabular}

Table 2. Image acquisition plans

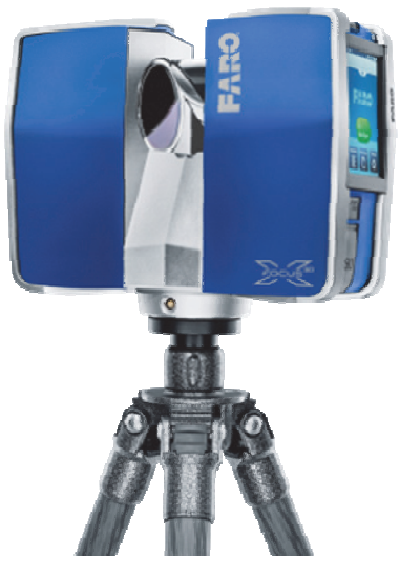

Figure 9. FARO Focus3D X330

\begin{tabular}{|l|l|}
\hline Range & $0.6 \mathrm{~m}-330 \mathrm{~m}$ \\
\hline Measurement speed & up to 976,000 points/second \\
\hline Ranging error & $\pm 2 \mathrm{~mm}$ \\
\hline Field of view & $\begin{array}{l}300^{\circ} \text { (vertical) } \\
360^{\circ} \text { (horizontal) }\end{array}$ \\
\hline Step size & $\begin{array}{l}0.009^{\circ} \text { (vertical) } \\
0.009^{\circ} \text { (horizontal) }\end{array}$ \\
\hline Weight & $5.2 \mathrm{~kg}$ \\
\hline Size & $240 \times 200 \times 100 \mathrm{~mm}$ \\
\hline Acquired data & $\mathrm{XYZ}$ Intensity, RGB \\
\hline
\end{tabular}

Table 3. Specification of FARO Focus3D X330
Infrastructure, Transport and Tourism of Japan, 2016c), we established three laser scanning stations in the target area as Figure 10 shows. Three point clouds were planned to be connected by using four reference spheres.

\section{RESULTS AND DISCUSSION}

From now on, we will show you the results of the experiment.

\subsection{UAV photogrammetry by QC730}

Figure 11 shows the image acquisition of Flight number 1 by QC730 with $\alpha 9000.891$ images were acquired in ten flight strips by QC730. The planned GSD was 10 millimetres.

Figure 12 shows the measurement errors of the nine check points against the different GSDs of the images by QC730. In all cases of 10 millimetres, 15 millimetres and 20 millimetres GSDs, the horizontal errors and the vertical errors of the nine check points satisfied the requirement of 50 millimetres. From these results, we conclude that the difference of GSD as to QC730 would not have a great influence on the measurement

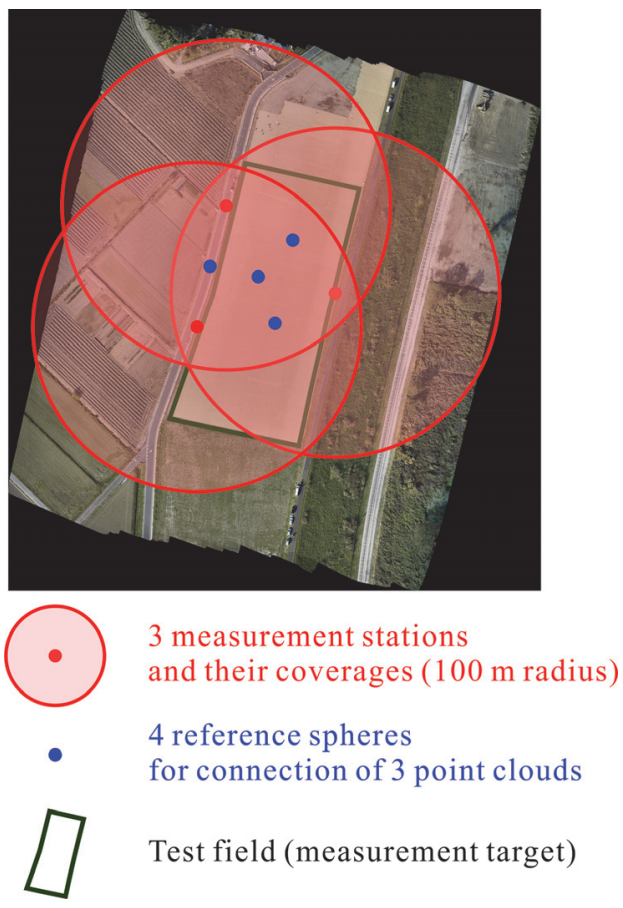

Figure 10. TLS observation plan

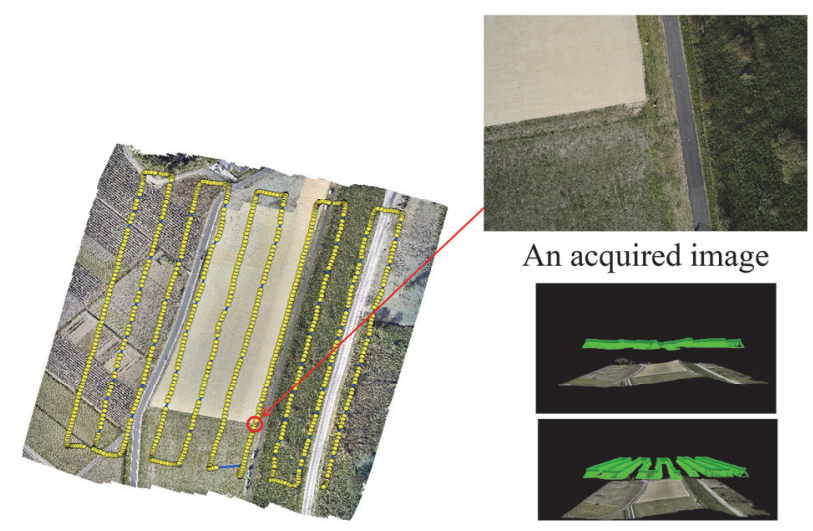

Image positions (horizontal) Image positions (vertical)

Figure 11. Flight number 1 by QC730 with $\alpha 9000$ 
accuracy.

Table 4 shows measurement errors of the nine check points by using all acquired images, namely $90 \%$ overlapping, and by using every second successive image, namely $80 \%$ overlapping. The results present a small difference in measurement accuracy by UAV photogrammetry between $90 \%$ and $80 \%$ in the overlapping ratio OL.

\subsection{UAV photogrammetry by Phantom 4}

Figure 13 shows the image acquisition of Flight number 4 by Phantom 4. 1135 images were acquired in 12 flight strips. The planned GSD was 10 millimetres.

Figure 14 shows the measurement errors of the nine check points against the different GSDs of the images by Phantom 4 . In all cases of 10 millimetres, 15 millimetres and 20 millimetres GSDs, the horizontal errors satisfied the requirement of 50 millimetres just like the case of QC730. On the contrary, the vertical errors did not satisfy the requirement. Just like the case of QC730, Figure 14 indicates that the difference of GSD would not have a great influence on the measurement accuracy.

Table 5 shows measurement errors of the nine check points by using all acquired images, namely $90 \%$ overlapping, and by using every second successive image, namely $80 \%$ overlapping.

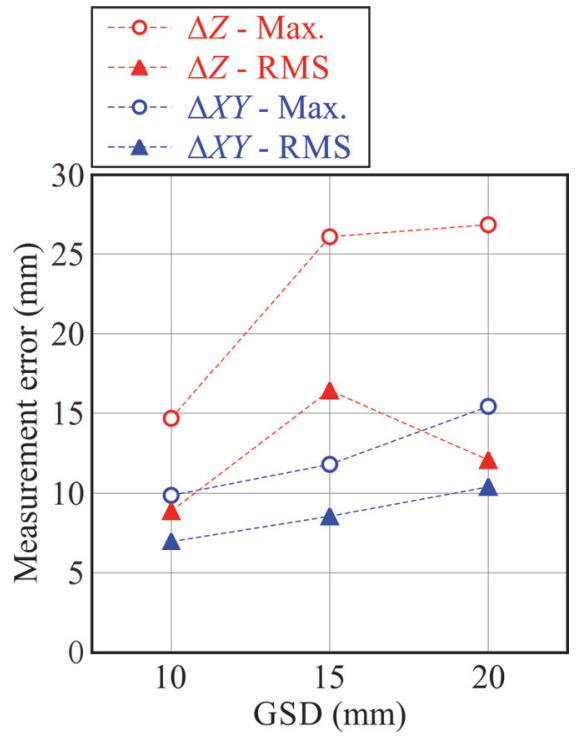

Figure 12. Measurement errors of 9 check points by QC730 vs. GSD

\begin{tabular}{|c|c|c|c|}
\hline \multicolumn{2}{|c|}{ QC730 } & $\Delta X Y(\mathrm{~mm})$ & $\Delta Z(\mathrm{~mm})$ \\
\hline OL & RMS & 7.0 & 8.9 \\
\hline $90 \%$ & Max. & 9.9 & 14.7 \\
\hline OL & RMS & 8.1 & 7.3 \\
\hline $80 \%$ & Max. & 12.3 & 15.1 \\
\hline
\end{tabular}

Table 4. Measurement errors of 9 check points by QC730 vs. overlapping ratio $\mathrm{OL}$
The results present a small difference in measurement accuracy by UAV photogrammetry between $90 \%$ and $80 \%$ in the overlapping ratio OL just like the case of QC730.

Figure 15 shows the vertical errors of six control points and nine check points in Flight number 4 of Phantom 4. Figure 16 shows the differences in height between the measurement results of Flight number 1 by QC730 and those of Flight number 4 by Phantom 4 at intervals of 0.1 metre. Both Figure 15 and Figure 16 suggest that systematic errors would exist in UAV photogrammetry by using Phantom 4 . The cause of the low accuracy by Phantom 4 is under investigation.

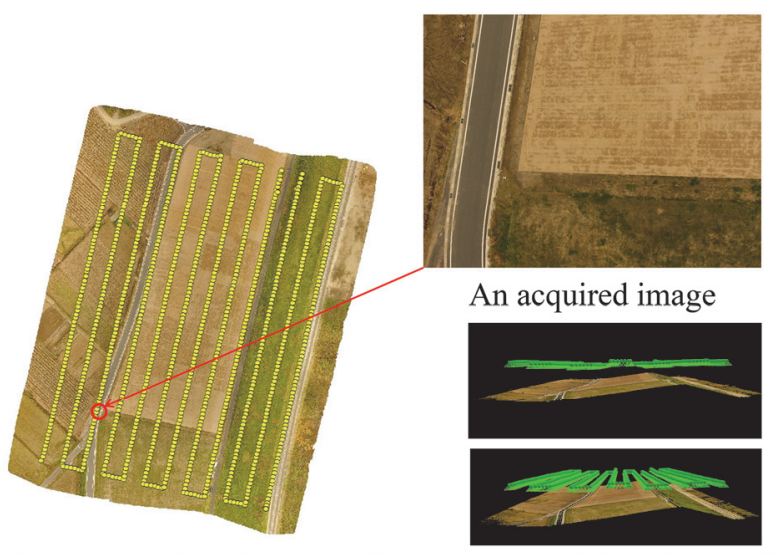

Image positions (horizontal) Image positions (vertical) Figure 13. Flight number 4 by Phantom 4

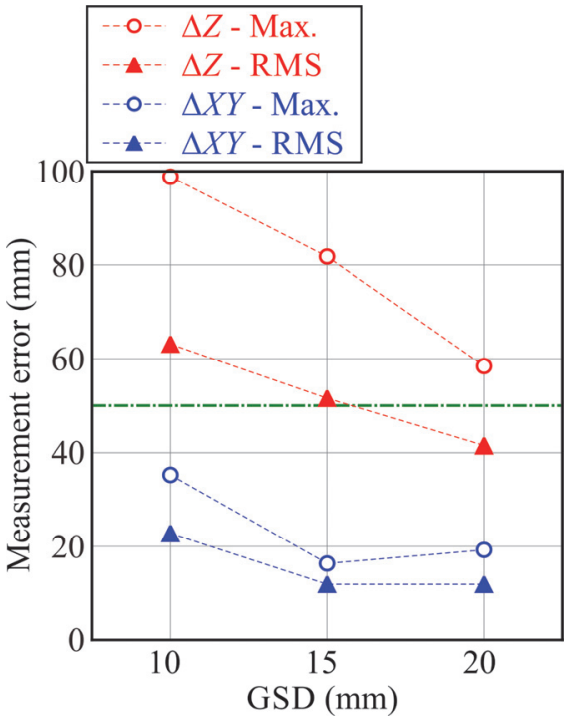

Figure 14. Measurement errors of 9 check points by Phantom 4 vs. GSD

\begin{tabular}{|c|c|c|c|}
\hline \multicolumn{2}{|c|}{ Phantom 4} & $\Delta X Y(\mathrm{~mm})$ & $\Delta Z(\mathrm{~mm})$ \\
\hline $\begin{array}{c}\text { OL } \\
90 \%\end{array}$ & RMS & 22.8 & 63.1 \\
\hline Max. & 35.3 & 98.8 \\
\hline $80 \%$ & RMS & 20.5 & 61.2 \\
\hline
\end{tabular}

Table 5. Measurement errors of 9 check points by Phantom 4 vs. overlapping ratio $\mathrm{OL}$ 


\subsection{TLS by Focus3D X330}

We verified the accuracy of TLS in the experiment according to the standard of TLS for "i-Construction." The verification for TLS is considerably simpler than that for UAV photogrammetry. The standard of TLS for "i-Construction" requires that the difference between a distance measured by TLS and a distance measured by using a total station or a surveying tape should be less than 20 millimetres.

We measured the distance between two points approximately 110 metres away from the scanner according to the standard of TLS for "i-Construction" as Figure 17 shows. Table 6 shows

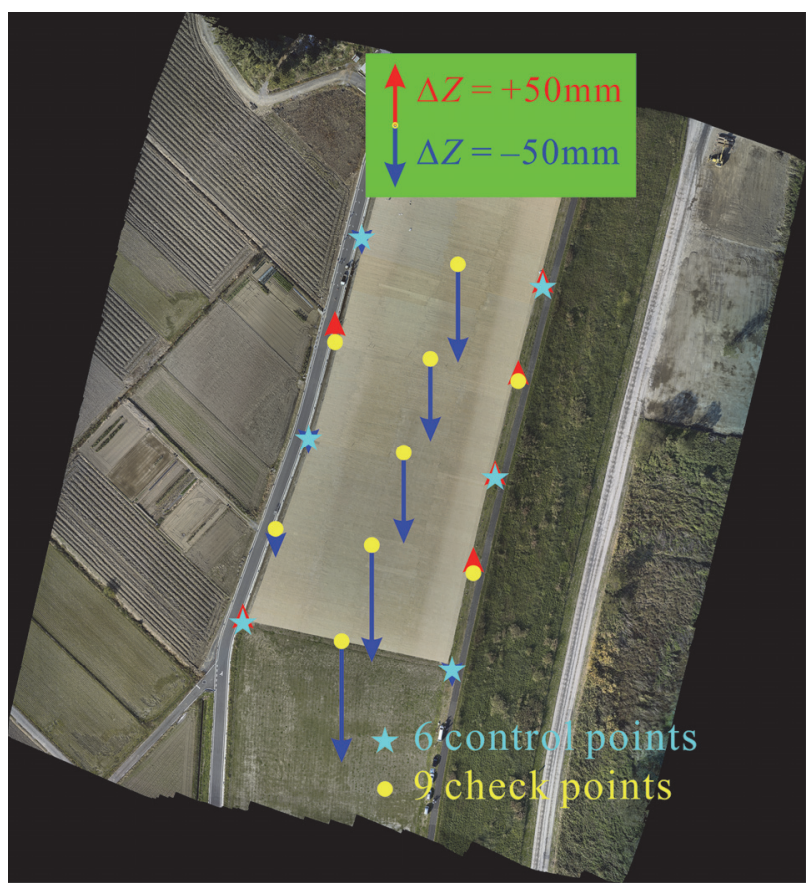

Figure 15. Vertical errors in Flight number 4 by Phantom 4

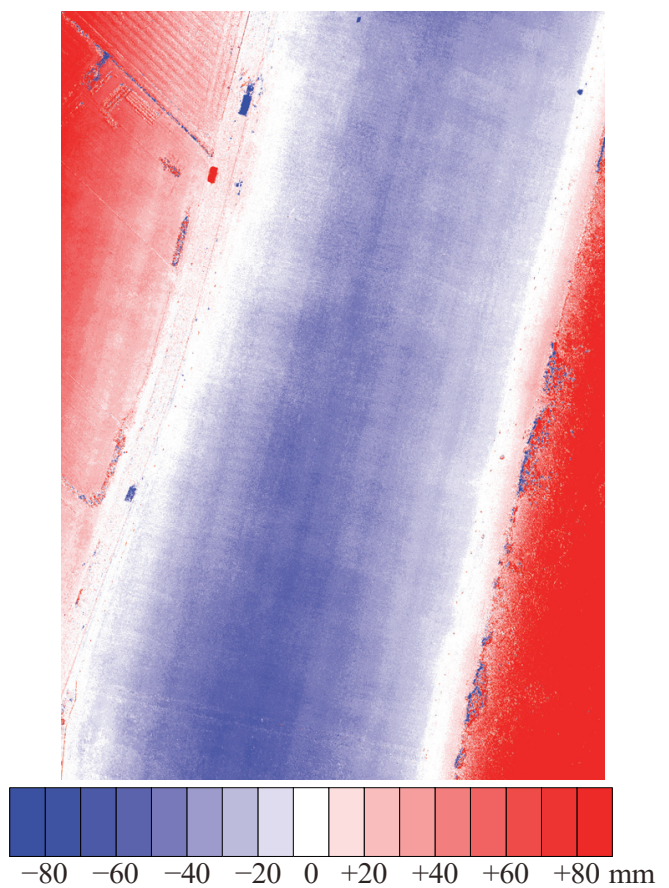

Figure 16. Differences in height between Flight number 1 by QC730 and Flight number 4 by Phantom 4 the distance measurement by TLS. The measurement result of the distance between Point 1 and Point 2 by TLS was 10.111 metres, while that by using a surveying tape was 10.121 metres. Since the difference between two distance measurements was 10 millimetres, our experiment passed the test.

The DSM at intervals of 0.1 metre obtained by TLS is shown in Figure 3.

\subsection{UAV photogrammetry vs. TLS}

Figure 18 shows the differences in height between UAV photogrammetry using a QC730 with an $\alpha 6000$ and TLS at intervals of 0.1 metre. We obtained 1,224,867 differences and Figure 19 shows the histogram of the differences.

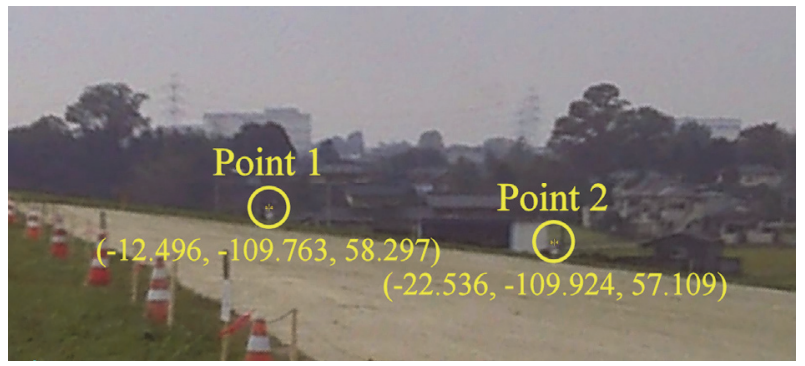

Figure 17. Verification of TLS by distance measurement

\begin{tabular}{|c|c|c|c|c|}
\hline Point & $X(\mathrm{~m})$ & $Y(\mathrm{~m})$ & $Z(\mathrm{~m})$ & distance \\
\hline 1 & -12.496 & -109.763 & 58.297 & $10.111 \mathrm{~m}$ \\
\hline 2 & -22.536 & -109.924 & 57.109 & \\
\hline
\end{tabular}

Table 6. Distance measurement by TLS

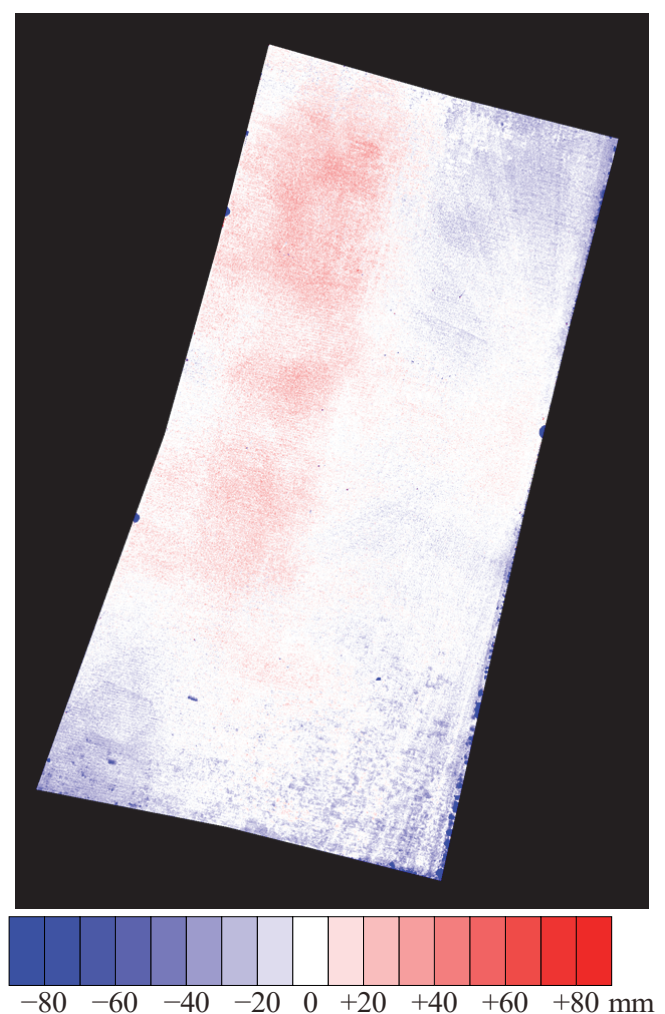

Figure 18. Differences in height between UAV photogrammetry and TLS 
The mean difference was -1 millimetres, and the RMS of the differences was 22 millimetres. Approximately $85 \%$ of the grid points had a difference smaller than 20 millimetres. And more than $95 \%$ of the grid points had a difference smaller than 30millimetres. The results indicate that the measurement accuracy of UAV photogrammetry using a QC730 and an $\alpha 6000$ would be essentially the same as that of TLS.

\section{CONCLUSIONS}

The experiment results indicate that the procedures of UAV photogrammetry using a QC730 and an $\alpha 6000$ and TLS using a Focus3D X330 following the standards for "i-Construction" would be feasible. Moreover the results show that UAV photogrammetry using a lower price UAV Phantom 4 was unable to satisfy the accuracy requirement. The results suggest systematic errors would exist in UAV photogrammetry using Phantom 4 as well. The cause of the low accuracy is under investigation.

We also found that the difference of image resolution on the ground would not have a great influence on the measurement accuracy in UAV photogrammetry, and that there would be a small difference in measurement accuracy by UAV photogrammetry between $90 \%$ and $80 \%$ in the overlapping ratio of successive images along a flight strip.

\section{ACKNOWLEDGEMENTS}

The authors are grateful to the Edogawa River Office, Kanto Regional Development Bureau, Ministry of Land, Infrastructure, Transport and Tourism of Japan, for assistance with the experiment.

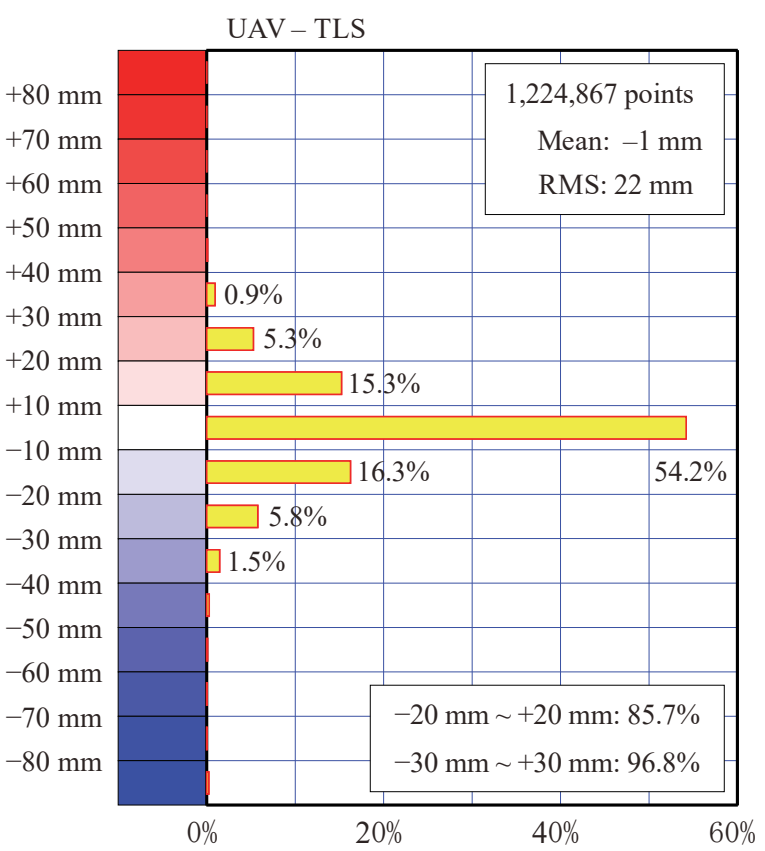

Figure 19. Histogram of differences in height between UAV photogrammetry and TLS

\section{REFERENCES}

Eisenbeiss, H., 2011. The Potential of Unmanned Aerial Vehicles for Mapping, Photogrammetrische Woche 2011, Dieter Fritsch (Ed.), Wichmann Verlag, Heidelberg, pp. 135145.

Gini, R., Pagliari, D., Passoni, D., Pinto, L., Sona, G., Dosso, P. 2013. UAV photogrammetry: block triangulation comparisons, The International Archives of the Photogrammetry, Remote Sensing and Spatial Information Sciences, Rostock, Germany, Vol. XL-1/W2, pp. 157-162.

Greiwe, A., Gehrke, R., Spreckels, V., Schlienkamp, A., 2013. Aspects of DEM Generation from UAS Imagery, The International Archives of the Photogrammetry, Remote Sensing and Spatial Information Sciences, Rostock, Germany, Vol. XL1/W2, pp. 151-156.

Gülch, E., 2011. Photogrammetric Evaluation of MultiTemporal Fixed Wing UAV Imagery, The International Archives of the Photogrammetry, Remote Sensing and Spatial Information Sciences, Zurich, Switzerland, Vol. XXXVIII1/C22., pp. 265-270.

Haala, N., Cramer, M., Weimer, F., Trittler, M., 2011. Performance Test on UAV-Based Photogrammetric Data Collection, The International Archives of the Photogrammetry, Remote Sensing and Spatial Information Sciences, Zurich, Switzerland, Vol. XXXVIII-1/C22, pp. 7-12.

Küng, O., Strecha, C., Beyeler, A., Zufferey, J.-C., Floreano, D., Fua, P., Gervaix, F., 2011. The Accuracy of Automatic Photogrammetric Techniques on Ultra-Light UAV Imagery, The International Archives of the Photogrammetry, Remote Sensing and Spatial Information Sciences, Zurich, Switzerland, Vol. XXXVIII-1/C22, pp. 125-130.

Matsuoka, R., Nagusa, I., Yasuhara, H., Mori, M., Katayama, T., Yachi, N., Hasui, A., Katakuse, M. Atagi, T., 2012. Measurement of Large-Scale Solar Power Plant by Using Images Acquired by Non-Metric Digital Camera on Board UAV, The International Archives of the Photogrammetry, Remote Sensing and Spatial Information Sciences, Melbourne, Australia, Vol. XXXIX, Part B1, pp. 435-440.

Ministry of Land, Infrastructure, Transport and Tourism of Japan, 2016a. Press Release issued in March 30, 2016, http://www.mlit.go.jp/common/001125408.pdf (10 July 2017).

Ministry of Land, Infrastructure, Transport and Tourism of Japan, 2016b. Draft of the Standard of Management System and Method of Finished Shape in Earthwork by UAV Photogrammetry.

Ministry of Land, Infrastructure, Transport and Tourism of Japan, 2016c. Draft of the Standard of Management System and Method of Finished Shape in Earthwork by Terrestrial Laser Scanning.

Vallet, J., Panissod, F., Strecha, C., Tracol, M., 2011. Photogrammetric Performance of an Ultra Light Weight Swinglet "UAV", The International Archives of the Photogrammetry, Remote Sensing and Spatial Information Sciences, Zurich, Switzerland, Vol. XXXVIII-1/C22, pp. 253258. 